\title{
One-Pot Synthesis of Some New s-Triazole Derivatives and Their Potential Application for Water Decontamination
}

\author{
Zeinab A. Hozien, Ahmed F. M. EL-Mahdy,* Laila S. A. Ali, Ahmad Abo Markeb, \\ and Hassan A. H. El-Sherief*
}

Cite This: ACS Omega 2021, 6, 25574-25584

Read Online

ABSTRACT: A rapid, efficient, and one-pot protocol has been developed for the synthesis of cyclized 2,6-dimethyl-5-substitutedthiazolo $[3,2-b]$-s-triazoles $(3 \mathbf{a}-\mathbf{c})$ through the interaction of 5 methyl-1H-s-triazole-3-thiol (1) with aliphatic ketones $(\mathbf{2 a}-\mathbf{d})$ in refluxing acetic acid in the presence of a catalytic amount of sulfuric acid $\left(\mathrm{AcOH} / \mathrm{H}^{+}\right)$while with aromatic ketones $(\mathbf{5 a}-\mathbf{d})$, a mixture of uncyclized 3-methyl-s-triazolylthioacetophenone derivatives $(6 \mathbf{6}-\mathbf{d})$ and cyclized 6-aryl-2-methyl-thiazolo[3,2-b]-s-triazoles $(7 \mathbf{a}-\mathbf{d})$ has been produced. With this catalytic system, inexpensive sulfuric acid was utilized as a catalyst, which prevented the production of poisonous and irritating halo carbonyl compounds. On the other hand, the interaction of $s$-triazole 1 with cyano compounds $(\mathbf{9 a}, \mathbf{b})$ afforded the corresponding 6-amino-2-methyl-5-substituted-thiazolo-

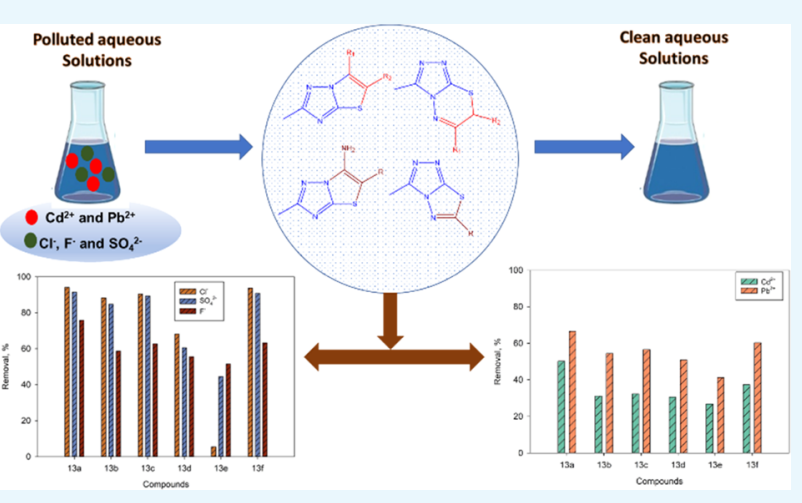
$[3,2-b]$-s-triazoles $(\mathbf{1 0 a}, \mathbf{b})$. Similarly, treatment of 4-amino-3-methyl-s-triazole-5-thiol (12) with aliphatic and aromatic ketones (2c and $\mathbf{5 a}-\mathbf{e})$ afforded directly 3-methyl-7H-s-triazolo[3,4-b]-1,3,4-thiadiazines (13a and $\mathbf{1 4 a - e})$. Further, reaction of $\mathbf{1 2}$ with cyano compounds $(\mathbf{9} \mathbf{a}, \mathbf{b})$ under the same reaction conditions yielded the corresponding 3-methyl-s-triazolo[3,4-b]-1,3,4-thiadiazole derivatives $(\mathbf{1 5 a}, \mathbf{b})$. The reaction mechanism was studied, and the structures of all novel compounds were verified using spectroscopy and elemental analysis. Moreover, the potential application of the synthesized compounds toward heavy metal ions and inorganic anion removal from aqueous solution has been investigated. The removal effectiveness for metal ions reached up to $76.29 \%$, while for inorganic anions it reached up to $100 \%$, indicating that such synthesized compounds are promising adsorbents for water remediation.

\section{INTRODUCTION}

In recent years, $s$-triazoles and their fused heterocyclic derivatives have received much interest due to their effective medicinal importance. There are many marked drugs, such as triazolam, alprazolam, and etizolam, containing the $s$-triazole group. $^{1-6}$ In the past decade, several applications of heterocyclic compounds containing nitrogen atoms have been reported. ${ }^{7-10}$ Biological activities; biomedical uses; and commercial applications such as dyes, insecticides, and herbicides of $s$-triazoles linked to heterocyclic rings have also been demonstrated. ${ }^{11-15}$ Recently, derivatives carrying the $s$ triazole moiety possess a wide spectrum of chemotherapeutic activities including antiviral, ${ }^{16}$ antifungal, ${ }^{17,18}$ anthelmintic, ${ }^{19}$ antitumor, $^{20-22}$ antibacterial, ${ }^{23}$ anti-inflammatory, ${ }^{24-26}$ antitubercular, ${ }^{27}$ analgesic, ${ }^{28,29}$ antipyretic, $^{30,31}$ and anticancer activities. $^{32}$ Indeed, some of these derivatives were actually active ingredients of drugs. ${ }^{33}$ Based on the literature survey, due to the amino and mercapto groups, which are prime nucleophilic sites for the synthesis of condensed heterocyclic rings, 4-amino-s-triazol-3-thiones were thought to be helpful tools for the synthesis of triazolothiadiazoles and triazolothia- diazines. ${ }^{34,35}$ We found that $s$-triazolo[3,4- $\left.b\right]-1,3,4$-thiadiazines and $s$-triazolo[3,4- $b]-1,3,4$-thiadiazoles can be synthesized by the treatment of 4-amino-5-substituted-3-mercapto-s-triazoles with $\alpha$-haloketone compounds and acids, respectively, in the presence of polyphosphoric acid. ${ }^{36-39}$ On the other hand, several reported methods were available for the synthesis of thiazolo[3,2-b]-s-triazoles, including alkylation of $s$-triazole-3thiol with phenacyl halides, 1,2-dihaloethane, or chloroacetic acid and the cyclization of 3 -allyl-s-triazole with iodine. ${ }^{40}$ Unfortunately, the synthesis of such $s$-triazolothiadiazines, $s$ triazolothiadiazoles, and thiazolo-s-triazoles required several steps, lengthy time, and the use of poisonous and irritating halo carbonyl chemicals with generally low yields. ${ }^{41}$ Our team successfully synthesized novel compounds containing $s$-triazole

Received: July 12, 2021

Accepted: September 10, 2021

Published: September 22, 2021 
Scheme 1. Reaction of 5-Methyl-1H-s-triazole-3-thiol (1) with Aliphatic and Aromatic Ketones

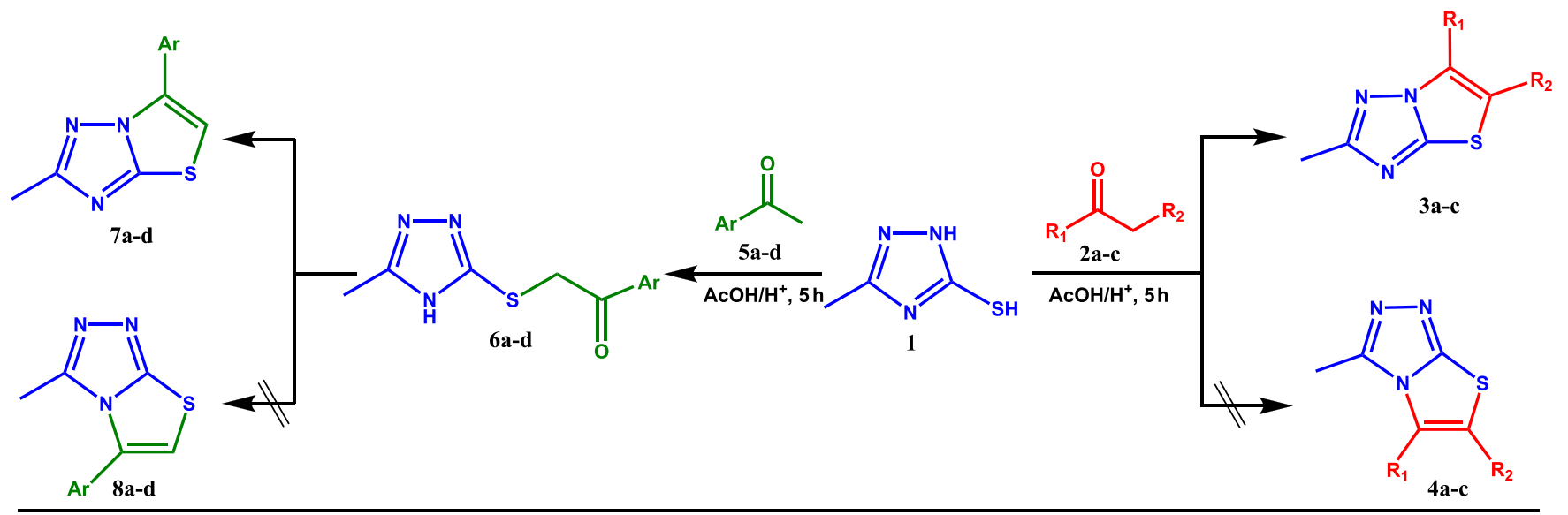<smiles>CC(=O)c1sc2nc(C)nn2c1C</smiles><smiles>Cc1ccc(-c2csc3nc(C)nn23)cc1</smiles>

moiety derivatives and demonstrated their efficiencies toward heavy metal removal from aqueous solution. ${ }^{41}$

Therefore, development of new $s$-triazole derivatives with the efficient ability to remove heavy metals and anion ions from water is strongly needed. As part of our ongoing research toward the development of variously critical substances, ${ }^{42-44}$ this work demonstrates the synthesis of novel derivatives of $s$ triazolo-thiadiazines, $s$-triazolo-thiadiazoles, and thiazolo-striazoles in a faster reaction time and with high reaction yields using the acetified acetic acid method that we have previously applied. ${ }^{45,46}$ Additionally, we demonstrate potential applications of such derivatives toward metals and anion removal from aqueous solution.

\section{RESULTS AND DISCUSSION}

Chemistry. In the context of our ongoing study on preparation of heterocyclic compounds using the acetified acetic acid method, in this study, we scrutinized the behavior of 5-methyl-1H-s-triazole-3-thiol (1) and 4-amino-5-methyl$4 H$-s-triazole-3-thiol (12) with various aliphatic and aromatic ketones, as well as cyano compounds having active methylene or a methyl group. Remarkably, the reaction of compound $\mathbf{1}$ with aliphatic ketones such as acetone, ethyl acetoacetate, acetylacetone, and benzoylacetone $(\mathbf{2} \mathbf{a}-\mathbf{d})$ in boiling acetic acid for $5 \mathrm{~h}$ in the presence of an acidic catalyst of sulfuric acid directly afforded 5,6-disubstituted-2-methyl-thiazolo[3,2-b]-striazoles $3 a-c$ or other possible isomeric products of 4,5disubstituted-3-methyl-thiazolo[2,3-c]-s-triazoles $4 \mathbf{a}-\mathbf{c}$ or a mixture of them. Thin-layer chromatography (TLC) revealed that the reaction produced only a single product (Scheme 1). Similarly, the reaction of compound 1 with aromatic ketones such as acetophenone, $p$-methylacetophenone, $p$-chloroacetophenone, and $p$-bromoacetophenone $(\mathbf{5 a}-\mathbf{d})$ under the same reaction conditions gave uncyclized 3-methyl-s-triazolylthioacetophenone derivatives $(6 a-d)$ in excellent yield, while increasing the reflux time to $10 \mathrm{~h}$ afforded a mixture of uncyclized compounds $\mathbf{6 a - d}$ and cyclized 6-aryl-2-methylthiazolo[3,2-b]-s-triazoles $(7 \mathbf{a}-\mathbf{d})$ or 5-aryl-3-methyl-thiazolo$[2,3-c]$-s-triazoles $(\mathbf{8 a}-\mathbf{d})$; this mixture was separated via column chromatography (Scheme 1).

The structures of all products were confirmed using Fouriertransform infrared (FTIR) and nuclear magnetic resonance (NMR) spectroscopies, in addition to mass spectroscopy. FTIR spectra of the isolated products indicated the presence of distinct absorption bands at wavenumbers of 2997-2849, 1608-1568, and $1485-1444 \mathrm{~cm}^{-1}$ for $\mathrm{C}-\mathrm{H}$ aliphatic, $\mathrm{C}=\mathrm{N}$, and $\mathrm{C}=\mathrm{C}$ vibration bonds, respectively (Figures $\mathrm{S} 1-\mathrm{S} 3$ ). While the FTIR spectra of compounds obtained from 
Scheme 2. Reaction of 5-Methyl-1H-s-triazole-3-thiol (1) with Cyano Compounds

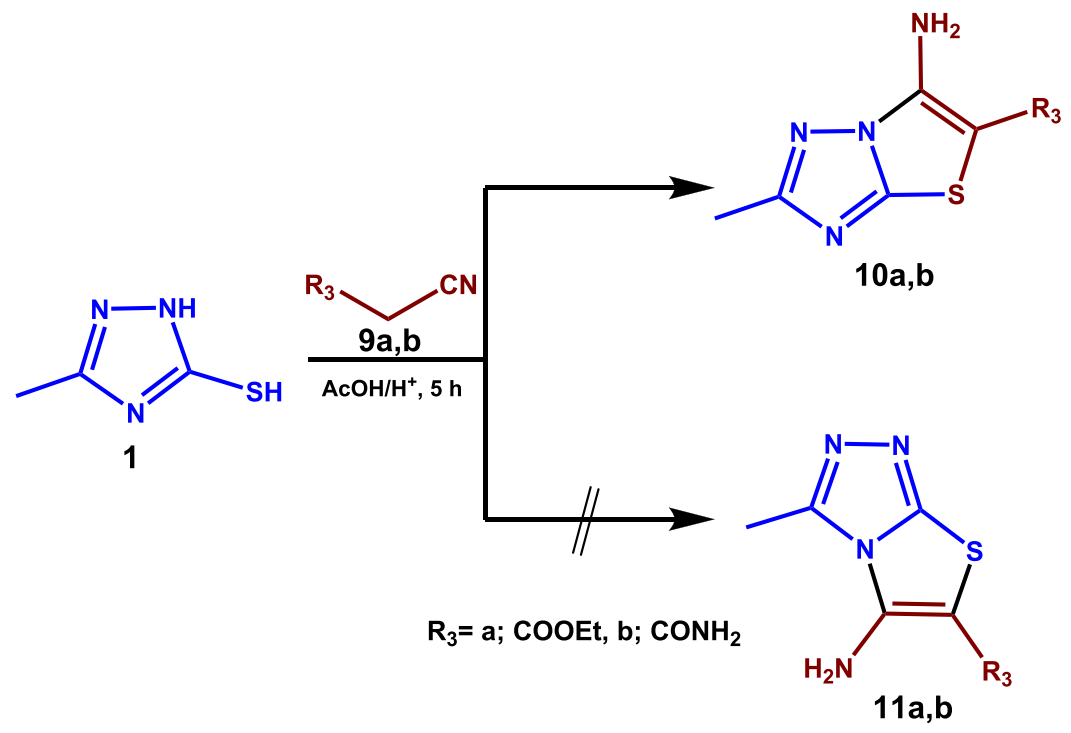

acetylacetone and benzoylacetone showed absorption bands at 1655-1637 $\mathrm{cm}^{-1}$ attributed to $\mathrm{CO}$ vibration bonds, in addition, compounds obtained from benzoylacetone featured a $\mathrm{C}-\mathrm{H}$ aromatic vibration band at $3068 \mathrm{~cm}^{-1}$. The ${ }^{1} \mathrm{H}-\mathrm{NMR}$ spectra of the isolated products showed a singlet signal at 2.47-2.58 and 2.54-2.66 ppm corresponding to the protons of the $\mathrm{CH}_{3}$ group in thiazolo and triazole rings, respectively (Figures S4-S6). The compound obtained from acetylacetone was characterized by a signal at $2.91 \mathrm{ppm}$ for $\mathrm{COCH}_{3}$. In addition, the isolated products from acetone and bezoylacetone showed signals at 6.56 and $7.53-7.80 \mathrm{ppm}$ attributed to the $\mathrm{C}-\mathrm{H}$ and aromatic protons, respectively. The ${ }^{13} \mathrm{C}-\mathrm{NMR}$ spectra of the isolated products from acetone and acetylacetone showed six signals at 165.49-167.96, 155.87-155.49, 135.50-106.76, 130.11-124.79, 15.05-14.67, and 13.15$12.63 \mathrm{ppm}$ for two triazole $\mathrm{C}=\mathrm{N}$, two thiazole $\mathrm{C}=\mathrm{C}, \mathrm{CH}_{3}$ triazole, and $\mathrm{CH}_{3}$ thiazole, respectively (Figures $\mathrm{S} 7$ and S8). In addition, compound $\mathbf{3 b}$ showed two additional peaks at 190.32 and $29.32 \mathrm{ppm}$ attributed to the $\underline{\mathrm{C}}=\mathrm{O}$ and $\mathrm{COC} \mathrm{H}_{3}$ groups, respectively (Figure S8). Furthermore, the predicted molecular ion peaks were observed in the mass spectra of the produced compounds, and the mass spectra of the compounds obtained from acetylacetone and bezoylacetone showed molecular ion $\mathrm{M}^{+}$peaks at $m / z$ values of 195 and 257, respectively. All of these findings cannot be used to determine which isomers, 3ac and $4 \mathbf{a}-\mathbf{c}$, are produced.

The regioselectivity of the cyclization step is strongly dependent on the difference in the electron density on the $\mathrm{N}-1$ and N-4 atoms of the starting compound 1. We have reported that the electron density of the N-1 atom is higher than that on the N-4 atom. ${ }^{18}$ Consequently, cyclization should be performed on the $\mathrm{N}-1$ atom, leading to the formation of the isomeric products $3 \mathbf{a}-\mathbf{c}$ rather than $4 \mathbf{a}-\mathbf{c}$. In addition, the electronic energy calculations confirmed that the isomeric products $3 \mathbf{a}-\mathbf{c}$ are more stable than the other isomeric products $\mathbf{4 a - c}$ (Table S1). It is worth noting that $s$-triazole $\mathbf{1}$ produced the same product $3 \mathbf{a}$ when treated with acetone or ethyl acetoacetate, which was confirmed by the lack of carbonyl and ethyl groups in FTIR (Figure S1) and NMR (Figures S4 and S7) spectra. This finding indicated the hydrolysis of the ester group, followed by decarboxylation, as shown in Scheme S1.

The FTIR spectra of compounds $\mathbf{6 a}-\mathbf{d}$ showed absorption bands at 3100-3018, 2923-2853, 1595-1582, and 1486$1431 \mathrm{~cm}^{-1}$ for $\mathrm{C}-\mathrm{H}$ aromatic, $\mathrm{C}-\mathrm{H}$ aliphatic, $\mathrm{C}=\mathrm{N}$, and $\mathrm{C}=$ $\mathrm{C}$ vibration bands, in addition to the appearance of the $\mathrm{N}-\mathrm{H}$ and $\mathrm{C}=\mathrm{O}$ absorption bands at 3355-3156 and 1713-1680 $\mathrm{cm}^{-1}$, respectively (Figures S9-S12). The ${ }^{1} \mathrm{H}-\mathrm{NMR}$ spectra of compounds $6 \mathbf{a}-\mathbf{d}$ featured a singlet signal at $2.28-2.39$ and 4.69-4.74 ppm attributed to protons of $\mathrm{CH}_{3}$ triazole and the $\mathrm{S}-\mathrm{CH}_{2}-\mathrm{CO}$ group, respectively. Additionally, aromatic protons and $\mathrm{NH}$ peaks were found at 7.35-8.09 and 13.56$13.58 \mathrm{ppm}$, respectively, in the isolated products $\mathbf{6 a}-\mathbf{d}$ (Figures S13-S16). The ${ }^{13} \mathrm{C}-\mathrm{NMR}$ spectra of products $6 \mathrm{a}$, 6c, and 6d showed signals at 193.06-193.88, 157.68-157.89, 153.86-154.45, and 31.26-38.86 ppm, respectively, for $\mathrm{C}=$ $\mathrm{O}$, two triazole $\mathrm{C}=\mathrm{N}$, and $\mathrm{S}-\mathrm{CH}_{2}-\mathrm{CO}$ groups, as well as the other carbons at the anticipated chemical shifts (Figures S17S19). The mass spectra of isolated products $\mathbf{6 a}, \mathbf{6 b}$, and $\mathbf{6 c}$ showed the expected molecular ion peaks of $233\left[\mathrm{M}^{+}\right], 247$ $\left[\mathrm{M}^{+}\right]$, and $267\left[\mathrm{Cl}^{35}, \mathrm{M}^{+}+1\right]$, respectively.

As we deduced before and according to the electronic energy calculations (Table S1), the cyclization reaction of compounds $\mathbf{6 a - d}$ should produce cyclized 6-aryl-2-methylthiazolo[3,2-b]-s-triazoles $(7 \mathbf{a}-\mathbf{d})$ rather than 5-aryl-3-methylthiazolo[2,3-c]-s-triazoles $(\mathbf{8 a}-\mathbf{d})$. The FTIR spectra of compounds $7 \mathrm{a}-\mathbf{d}$ showed absorption bands at 3091-3027, 2989-2848, 1598-1540, and 1478-1445 $\mathrm{cm}^{-1}$ for $\mathrm{C}-\mathrm{H}$ aromatic, $\mathrm{C}-\mathrm{H}$ aliphatic, $\mathrm{C}=\mathrm{N}$, and $\mathrm{C}=\mathrm{C}$ vibration bands, respectively (Figures S20-S23). All compounds 7a-d lacked $\mathrm{NH}$ absorption bands. The ${ }^{1} \mathrm{H}-\mathrm{NMR}$ spectra of isolated products $7 \mathbf{a}-\mathbf{d}$ showed signals at $2.55-2.70$ and 7.14-8.08 ppm attributed to protons of $\mathrm{CH}_{3}$ triazole and $\mathrm{C}-\mathrm{H}$ aromatic, respectively (Figures S24-S26). In addition, compound $7 \mathbf{b}$ showed a singlet $\mathrm{CH}_{3}$ signal at $2.44 \mathrm{ppm}$. The mass spectra of isolated products $7 \mathbf{b}, 7 \mathbf{c}$, and $7 \mathbf{d}$ showed the expected molecular ion peaks of $229.20\left[\mathrm{M}^{+}\right], 249\left[\mathrm{Cl}^{35}, \mathrm{M}^{+}\right], 251$ $\left[\mathrm{Cl}^{37}, \mathrm{M}^{+}\right], 293\left[\mathrm{Br}^{79}, \mathrm{M}^{+}\right]$, and $295\left[\mathrm{Br}^{81}, \mathrm{M}^{+}\right]$, respectively.

When $s$-triazole 1 reacted with cyano compounds such as ethyl cyanoacetate, cyanoacetamide, and malononitrile $(9 a-c)$, it afforded 6-amino-2-methyl-thiazolo[3,2-b]-s-triazoles 10a,b, 
Scheme 3. Reaction of 4-Amino-5-methyl-4H-s-triazole-3-thiol (12) with Ketones and Cyano Compounds

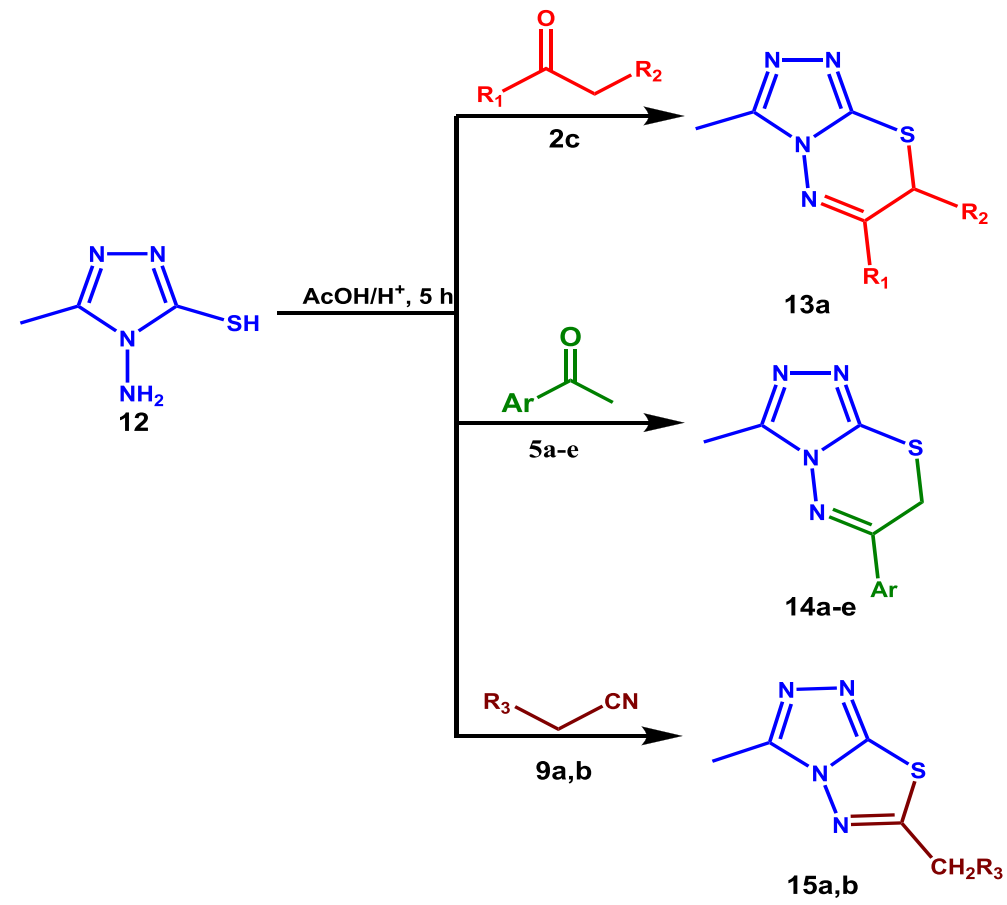<smiles>CC1=Nn2c(C)nnc2SC1C(=O)c1ccccc1</smiles><smiles>Cc1nnc2n1N=C(c1ccccc1)CS2</smiles>

$13 a$<smiles>Cc1nnc2n1N=C(c1ccc(Br)cc1)CS2</smiles>

14d<smiles>Cc1nnc2n1N=C(c1ccccc1O)CS2</smiles>

$14 e$<smiles>Cc1ccc(C2=Nn3c(C)nnc3SC2)cc1</smiles>

$14 b$<smiles>Cc1nn2c(C)nnc2s1</smiles>

$15 a$<smiles>Cc1nnc2n1N=C(c1ccc(Cl)cc1)CS2</smiles>

$14 \mathrm{c}$<smiles>Cc1nnc2sc(CC(N)=O)nn12</smiles>

other possible isomeric products 4-amino-3-methyl-thiazolo$[2,3-c]-s$-triazole $1 \mathbf{1} \mathbf{a}, \mathbf{b}$, or a mixture of them. However, based on TLC, the reaction gave only a single product (Scheme 2). According to the electronic energy calculations (Table S1), the reaction product should be the more stable $\mathbf{1 0 a}, \mathbf{b}$ rather than the other isomeric products $1 \mathbf{1} \mathbf{a}, \mathbf{b}$ (Scheme 2). It is recognizable that the cyano group $(9 \mathrm{c}, \mathrm{R}=\mathrm{CN})$ undergoes hydrolysis to the amide derivative $\mathbf{1 0 b}$.

The FTIR spectra of compounds 10a,b showed absorption bands at 3439-3270, 2977-2850, 1682-1667, 1606-1567, and $1499-1477 \mathrm{~cm}^{-1}$ for $\mathrm{NH}_{2}, \mathrm{C}-\mathrm{H}$ aliphatic, $\mathrm{C}=\mathrm{O}, \mathrm{C}=\mathrm{N}$, and $\mathrm{C}=\mathrm{C}$ vibration bands, respectively (Figures S27 and S28).

${ }^{1} \mathrm{H}-\mathrm{NMR}$ spectra of compounds 10a,b showed singlet signals at $\delta=2.43-2.53$ and 6.26-7.27 (exchange with $\left.\mathrm{D}_{2} \mathrm{O}\right)$ ppm attributed to protons of $\mathrm{CH}_{3}$ triazole and $\mathrm{NH}_{2}$, respectively (Figures S29 and S30). Additionally, the isolated product from ethyl cyanoacetate 10a showed a triplet signal at $\delta=1.35-1.38$ ppm for $\mathrm{CH}_{2} \underline{\mathrm{C}}_{3}$ and a quadruple signal at $\delta=$ 4.31-4.35 ppm for $\mathrm{CH}_{2} \mathrm{CH}_{3}$ (Figure S29), while product $10 \mathrm{~b}$ showed singlet signal at $\delta=7.53 \mathrm{ppm}$ attributed to $\mathrm{CONH}_{2}$ 
(Figure S30). The ${ }^{13} \mathrm{H}-\mathrm{NMR}$ spectrum of 10a, for example, exhibited five signals at $\delta=167.94,164.13,156.15,140.92$, $130.29 \mathrm{ppm}$ attributed to $\underline{\mathrm{COOEt}}$, two triazole $\mathrm{C}=\mathrm{N}$, and two thiazole $\mathrm{C}=\mathrm{C}$, respectively. Also, the isolated product 10a showed two ethyl signals at $\delta=61.10$ and $14.42 \mathrm{ppm}$ (Figure S31). The mass spectra of 10a provided the expected molecular ion peak of $226.26\left[\mathrm{M}^{+}\right]$.

Under the same reaction conditions, we studied the behavior of 4-amino-5-methyl-4H-s-triazole-3-thiol (12) with aliphatic ketone (2c) and aromatic ketones (5a-e), which confirmed the formation of 7-benzoyl-3,6-dimethyl-s-triazolo[3,4-b]1,3,4-thiadiazine (13a) and 3-methyl-7H-s-triazolo[3,4-b]1,3,4-thiadiazines $(\mathbf{1 4 a}-\mathbf{e})$, respectively (Scheme 3$)$. The FTIR spectrum of compound 13a was characterized by several absorption bands at $3069,2926,1592$, and $1467 \mathrm{~cm}^{-1}$ for C$\mathrm{H}$ aromatic, $\mathrm{C}-\mathrm{H}$ aliphatic, $\mathrm{C}=\mathrm{O}, \mathrm{C}=\mathrm{N}$, and $\mathrm{C}=\mathrm{C}$ vibrations, respectively (Figure S32), while the FTIR spectra of the products $14 \mathbf{a}-\mathbf{e}$ featured several absorption bands at 3072-3030, 2985-2904, 1608-1537, and 1473-1448 $\mathrm{cm}^{-1}$ for $\mathrm{C}-\mathrm{H}$ aromatic, $\mathrm{C}-\mathrm{H}$ aliphatic, $\mathrm{C}=\mathrm{N}$, and $\mathrm{C}=\mathrm{C}$ vibrations, respectively (Figures S33-S37). In addition, compound 14e showed a specific $\mathrm{OH}$ absorption band at $3265 \mathrm{~cm}^{-1}$ (Figure S37). The ${ }^{1} \mathrm{H}-\mathrm{NMR}$ spectra of compound 13a featured a series of singlet signals at 5.00, 2.50, and 2.30 ppm, which could be assigned to the $\mathrm{C}-\mathrm{H}$, triazole $\mathrm{CH}_{3}$, and thiadiazine $\mathrm{CH}_{3}$ groups, respectively, as well as the aromatic protons in a chemical shift range of 7.60-7.30 ppm (Figure S38). The ${ }^{1} \mathrm{H}-\mathrm{NMR}$ spectra of products $\mathbf{1 4} \mathbf{a}-\mathbf{e}$ featured the appearance of a singlet signal at $\delta=3.95-4.37$, which is attributed to cyclic $\mathrm{CH}_{2}$, and multiplet signals at $\delta=6.94-7.97$ ppm attributable to the $\mathrm{CH}$ aromatic (Figures S39-S43). Compound 14e showed a singlet signal at $10.54 \mathrm{ppm}$ for the $\mathrm{OH}$ group (exchange with $\mathrm{D}_{2} \mathrm{O}$ ) (Figure S43). The ${ }^{13} \mathrm{C}-\mathrm{NMR}$ spectra of compounds $14 \mathrm{c}$ and $14 \mathrm{e}$ exhibited four signals at $156-151,151-140,139-132$, and $25-23 \mathrm{ppm}$ for $\mathrm{C}_{6}=\mathrm{N}$, two triazole $\mathrm{C}=\mathrm{N}$, and $\mathrm{CH}_{2}$ of thiadiazine, respectively (Figures S44 and S45). In addition, compound 14e showed a peak at $150 \mathrm{ppm}$ attributed to the $\mathrm{C}-\mathrm{OH}$ group (Figure S45). The mass spectra of products $14 a, 14 c$, and $14 \mathrm{e}$ provided the expected molecular ion peaks of $229\left[\mathrm{M}^{+}\right], 264\left[\mathrm{Cl}^{35}, \mathrm{M}^{+}\right], 266$ $\left[\mathrm{Cl}^{37}, \mathrm{M}^{+}\right]$, and $246\left[\mathrm{M}^{+}\right]$, respectively.

When compound 12 was reacted with ethyl cyanoacetate, the $s$-triazolo $[3,4-b]-1,3,4$-thiadiazole derivative $\left(15 \mathrm{a}, \mathrm{R}_{1}=\mathrm{H}\right)$ was obtained, but when malononitrile or cyanoacetamide was used, the $s$-triazolo[3,4-b]-1,3,4-thiadiazole derivative (15b, $\mathrm{R}_{1}=\mathrm{CONH}_{2}$ ) was formed (Scheme 3). The FTIR spectra of isolated products 15a,b showed the absorption bands at 29912851, 1600-1541, and $1480-1471 \mathrm{~cm}^{-1}$ for $\mathrm{C}-\mathrm{H}$ aliphatic, $\mathrm{C}=\mathrm{N}$, and $\mathrm{C}=\mathrm{C}$ vibration bands, respectively (Figures S46 and S47). In addition, compound $\mathbf{1 5 b}$ showed specific absorption bands at 3370-3214 and $1693 \mathrm{~cm}^{-1}$, which are attributed to $\mathrm{NH}_{2}$ and $\mathrm{CO}$ amide groups, respectively (Figure S47). The appearance of singlet signals at $\delta=4.45$ and 7.08 (exchange with $\mathrm{D}_{2} \mathrm{O}$ ) ppm in the ${ }^{1} \mathrm{H}-\mathrm{NMR}$ spectrum of compound $\mathbf{1 5 b}$ is attributed to the $\mathrm{CH}_{2}$ and $\mathrm{NH}_{2}$ groups, respectively (Figure S49). Additionally, the isolated product 15a showed a singlet signal at $\delta=2.29$ and $2.45 \mathrm{ppm}$ attributed to $\mathrm{CH}_{3}$ and $\mathrm{CH}_{3}$ triazole, respectively (Figure $\mathrm{S} 48$ ). The ${ }^{13} \mathrm{C}$ NMR spectra of compounds $15 \mathbf{a}$ and $\mathbf{1 5 b}$ featured a set of signals at 153.79-150.72 and 9.97-9.95 ppm for the $\mathrm{C}_{6}=\mathrm{N}$ and $\mathrm{CH}_{3}$ triazole groups, respectively (Figures $\mathrm{S} 50$ and S51). In addition, compound 15a exhibited $\mathrm{CH}_{3}$ thiadiazole at 23.63 ppm (Figure S50), while compound $\mathbf{1 5 b}$ exhibited the methylene and carbonyl groups at $\delta=23.90$ and 167.15 ppm, respectively (Figure S51). The mass spectra of isolated products 14a,b showed the expected molecular ion peaks of $154.10\left[\mathrm{M}^{+}\right]$and $197.22\left[\mathrm{M}^{+}\right]$, respectively.

Proposed Mechanism. The proposed mechanisms for formation of isolated products $3 a-c$ and $7 a-d, 10 a, b$, and 15a,b are summarized in Schemes $S 2-S 4$, respectively. For $3 \mathbf{a}-\mathbf{c}$ and $7 \mathbf{a}-\mathbf{d}$, the $s$-triazole is initially oxidized to form the disulfide intermediate 16, which is followed by the nucleophilic attack of the enolate form of the ketone to give the S-alkylation intermediate 17. This formed intermediate then undergoes intramolecular cyclization to directly give the desired products $3 \mathbf{a}-\mathbf{c}$ and $7 \mathbf{a}-\mathbf{d}$ (Scheme S2). The mechanism for formation of 6-amino-2-methyl-thiazolo[3,2-b]-s-triazoles (10a,b) may proceed via the formed disulfide 16 , followed by a nucleophilic attack by the imine form on the dimeric disulfide to give the carbonium ion 18, which then undergoes intramolecular cyclization to produce the cyclized imino structures 19 . Protonation of 19 in the presence of an acid medium produced the cyclized carbonium ion 20, followed by deportation to yield the cyclized compound 10a,b (Scheme S3). On the other hand, formation of $s$-triazolo[3,4-b]-1,3,4-thiadiazoles (15a,b) can be illustrated by the nucleophilic attack of the amino group of the starting $s$-triazole (12) on the cyano group of the nitrile compound $(9 a-c)$ to form the uncyclized imines $(21)$. The formed imine 21 then undergoes intramolecular cyclization with elimination of ammonia molecule to produce the cyclized products $\mathbf{1 5 a , b}$ (Scheme S4). It is notable that the ester group of compound $15(\mathrm{R}=\mathrm{COOEt})$ formed from 9a undergoes hydrolysis followed by decarboxylation to produce the product 15a $\left(R_{1}=H\right)$. The cyano group of compound $14\left(R_{1}=C N\right)$ derived from 9c also undergoes hydrolysis to produce $14 \mathrm{~b}$ $\left(\mathrm{R}_{1}=\mathrm{CONH}_{2}\right)$.

Screening of Contaminant Removal from Aqueous Solution. The removal efficiencies of different contaminants from aqueous solutions using the thiazolo-s-triazole (compounds $3 \mathbf{a}-\mathbf{c}$ and $7 \mathbf{a}-\mathbf{d}$ ), s-triazolylthioacetophenone (compounds $\mathbf{6 a - d}$ ), 6-amino-thiazolo-s-triazole (compounds 10a and 10b), s-triazolo[3,4-b]-1,3,4-thiadiazines (compounds 13a and 14a-e), and $s$-triazolo[3,4-b]-1,3,4-thiadiazole (compounds 15 a and $15 b$ ) derivatives in this work were studied. For instance, the contaminants under investigation were cadmium and lead ions as heavy metal ions, and the anions were fluoride, chloride, and sulfate. Batch adsorption tests were used in the adsorption studies to assess the efficacy of the produced compounds based on the s-triazole moiety. Residual contaminant concentration in the aqueous solution after $24 \mathrm{~h}$ of adsorption $\left(C_{\mathrm{e}}\right)$ was estimated via the related analytical technique, which has been previously described, ${ }^{47,48}$ and the removal efficiency of the synthesized compounds was calculated using eq 1 . Adsorption experiments are based either on the reported typical concentration in water or on the maximum contaminated level (MCL) in drinking water. For instance, $10 \mathrm{mg} / \mathrm{L}$ was selected as the initial fluoride concentration because its MCL in water is $1.5 \mathrm{mg} / \mathrm{L}$ according to WHO. In the case of fluoride, its content in groundwater in many areas has been observed to range from less than $1.0 \mathrm{mg} /$ $\mathrm{L}$ to more than $35.0 \mathrm{mg} / \mathrm{L}$. In addition, the initial concentrations of chloride and sulfate ions were the same as the MCL $(250 \mathrm{mg} / \mathrm{L})$. Furthermore, $10 \mathrm{mg} / \mathrm{L}$ lead $\left(\mathrm{Pb}^{2+}\right)$ and cadmium ions $\left(\mathrm{Cd}^{2+}\right)$ as the initial concentration was selected as wastewater contains $10-100 \mathrm{mg} / \mathrm{L}$ heavy metal ion contaminant. All of the experiments were performed at $\mathrm{pH}$ 5.5. 


$$
\% R=\frac{\left(C_{0}-C_{\mathrm{e}}\right)}{C_{0}} \times 100
$$

where $C_{0}$ and $C_{\mathrm{e}}$ are the initial and equilibrium concentrations of the contaminants, respectively.

Heavy Metal Ion Removal. Heavy metal ions such as cadmium and lead are known to be toxic and presage a risk to living systems when released into the environment. While poisoning of water with lead ions causes reduced intelligence, renal failure, and increased risk of cardiovascular diseases, contamination with cadmium ion leads to chronic anemia and endocrine disruptor and interferes with calcium regulation in biological systems. ${ }^{49}$ Adsorption technique allows for fast, costeffective, reusable, and selective elimination of pollutants from aqueous solutions using synthetic chemicals. The adsorption process is used in the purifying of water where the dissolved pollutants are transferred to the adsorbent surface. Moreover, most technologies used in water treatment cost from 10 to 450 $\mathrm{US} \$ / \mathrm{m}^{3}$, while the cost of the adsorption method ranges from 5 to $200 \mathrm{US} \$ / \mathrm{m}^{3}$. The variation of the cost is relative to the adsorbent. ${ }^{50}$ The potential of adsorption increases as the $\mathrm{pH}$ value is increased in the range of $2-5$, but there is little increase from $\mathrm{pH} 5$ to $6 .^{51}$ Therefore, the $\mathrm{pH}$ value of 5.5 was selected. Figures $1-3$ illustrate the removal percentage of $\mathrm{Pb}^{2+}$

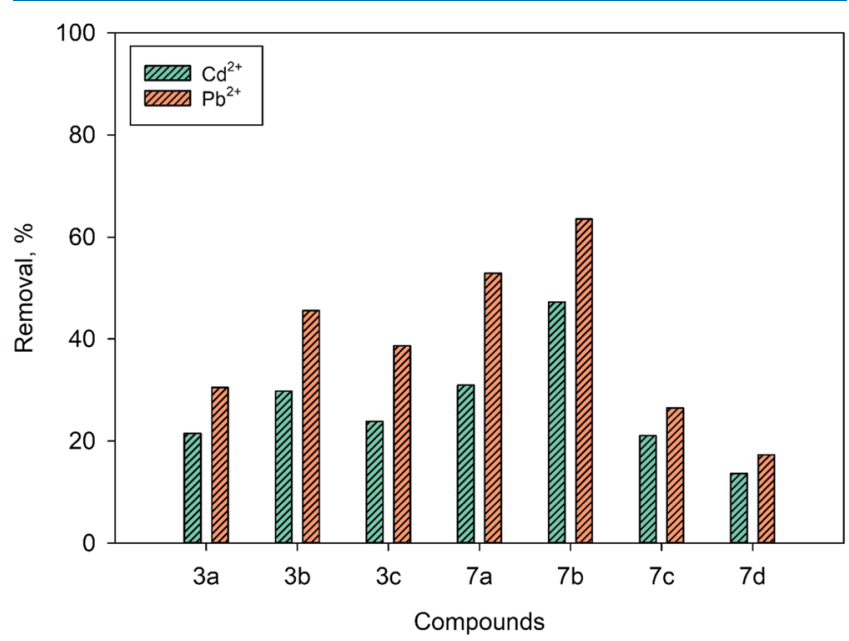

Figure 1. Lead and cadmium ion removal using 1,3-thiazolo-s-triazole derivatives.

and $\mathrm{Cd}^{2+}$ ions' contaminants from aqueous solutions using compounds $3 a-c$ and $7 a-d, 6 a-d$, and $13 a$ and $14 a-e$, respectively. Compounds $3 \mathrm{a}-\mathrm{c}$ show the range of removal to be $21.46-29.75 \%$ in the case of $\mathrm{Cd}^{2+}$ and $30.49-45.95 \%$ in the case of $\mathrm{Pb}^{2+}$. It was found that the presence of the carbonyl group enhanced the efficacy of the removal of heavy metal ions compared to the absence of the $-\mathrm{C}=\mathrm{O}$ group as illustrated in Figure 1. This could be attributed to the ease of complex formation by the carbonyl group. In addition, $\mathbf{3 b}$ shows higher removal for both $\mathrm{Pb}^{2+}$ and $\mathrm{Cd}^{2+}$ than $3 \mathrm{c}$ due to the presence of $-\mathrm{CH}_{3}$ as the donating group, where 45.95 and $29.75 \%$ removal of $\mathrm{Pb}^{2+}$ and $\mathrm{Cd}^{2+}$, respectively, were obtained. Also, 13.6547.26 and 17.31-63.53\% efficiencies were found for $\mathrm{Cd}^{2+}$ and $\mathrm{Pb}^{2+}$ removal, respectively, using $7 \mathrm{a}-\mathrm{d}$ compounds. Interestingly, the same behavior of heavy metal ion removal as that in our previous work was obtained, ${ }^{41}$ where the presence of a donating group such as methyl in the para position of the aromatic amine enhances the efficiencies of removal than the absence or presence of a withdrawing group in the para position. For instance, the removal of $\mathrm{Pb}^{2+}$ and $\mathrm{Cd}^{2+}$ was 63.53 and $47.26 \%$ using $7 \mathbf{b}$, while 52.91 and $30.96 \%$ removal was observed using $7 \mathbf{a}$, respectively. Although the removal efficiencies were decreased when bromo and chloro groups were in the para position, the efficacy of the chloro group was higher than that of the bromo group. For instance, 26.49 and $21.03 \%$ removal of $\mathrm{Pb}^{2+}$ and $\mathrm{Cd}^{2+}$ was found using $7 \mathrm{c}$, while $7 \mathrm{~d}$ shows 17.31 and $13.65 \%$ removal of $\mathrm{Pb}^{2+}$ and $\mathrm{Cd}^{2+}$, respectively.

Likewise, high removal efficiency was observed using $\mathbf{1 0 b}$ with 64.77 and $48.26 \%$ removal of $\mathrm{Pb}^{2+}$ and $\mathrm{Cd}^{2+}$, respectively, in comparison with $10 \mathrm{a}$, where the removal of $\mathrm{Pb}^{2+}$ and $\mathrm{Cd}^{2+}$ was found to be 58.05 and $35.74 \%$, respectively. The reason for this could be attributed to the presence of the $-\mathrm{CONH}_{2}$ group (amide group) in $\mathbf{1 0 b}$ and $-\mathrm{COOC}_{2} \mathrm{H}_{5}$ (ester group) in $\mathbf{1 0 a}$ that enhances complex formation.

Besides, compounds 6a-d (s-triazolylthioacetophenone) displayed the highest efficiencies compared to compounds $7 \mathbf{a}-\mathbf{d}$ and the same trend as in the presence or the absence of donating or withdrawing groups, as shown in Figure 2. This

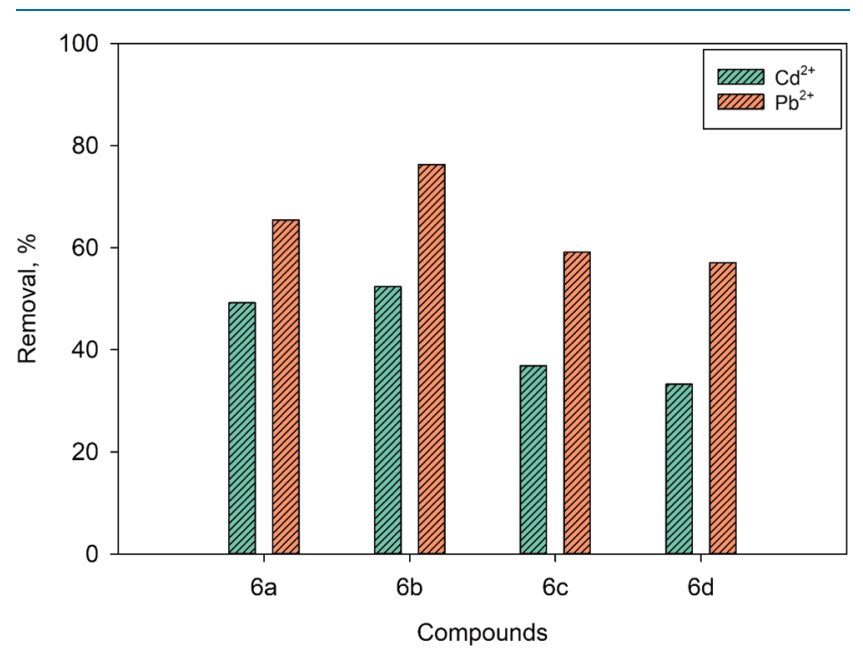

Figure 2. Lead and cadmium ion removal using $s$-triazolylthioacetophenone derivatives.

could be ascribed to a lack of $-\mathrm{NH}$ absorption bands in compounds $7 \mathbf{a}-\mathbf{d}$. For example, the highest value of removal was found in the case of the presence of the methoxy group in the para position against the absence of the donating group with 76.29 and $52.39 \%$ for $\mathrm{Pb}^{2+}$ and $\mathrm{Cd}^{2+}$ using $\mathbf{6 b}$, while $\mathbf{6 a}$ shows 65.44 and $49.22 \%$ removal of $\mathrm{Pb}^{2+}$ and $\mathrm{Cd}^{2+}$, respectively. Also, low removal of heavy metal ions was obtained in the case of the presence of the withdrawing group in the para position. For example, the chloro group in the para position, $6 \mathrm{c}$, demonstrated $\mathrm{Pb}^{2+}$ and $\mathrm{Cd}^{2+}$ capacities of 59.17 and $36.84 \%$, respectively, while 57.05 and $33.21 \%$ removal of $\mathrm{Pb}^{2+}$ and $\mathrm{Cd}^{2+}$ was observed using $\mathbf{5 d}$ in the case of the presence of the bromo group in the para position.

Moreover, moderate to high capacities of $\mathrm{Pb}^{2+}$ and $\mathrm{Cd}^{2+}$ removal were observed using $s$-triazolo $[3,4 \mathrm{~b}][1,3,4]$ thiadiazines (13a and $14 a-e)$ and $s$-triazolo[3,4-b]-1,3,4thiadiazole (15a and $\mathbf{1 5 b}$ ) derivatives. Figure 3 illustrates removal efficiencies of $\mathrm{Pb}^{2+}$ in the order of $66.55,60.29,56.60$, $54.47,50.89$, and $41.26 \%$ and for $\mathrm{Cd}^{2+}$ as 50.24, 37.36, 32.36, $31.20,30.61$, and $26.85 \%$ using 13a, 14e, 14b, 14a, 14c, and 


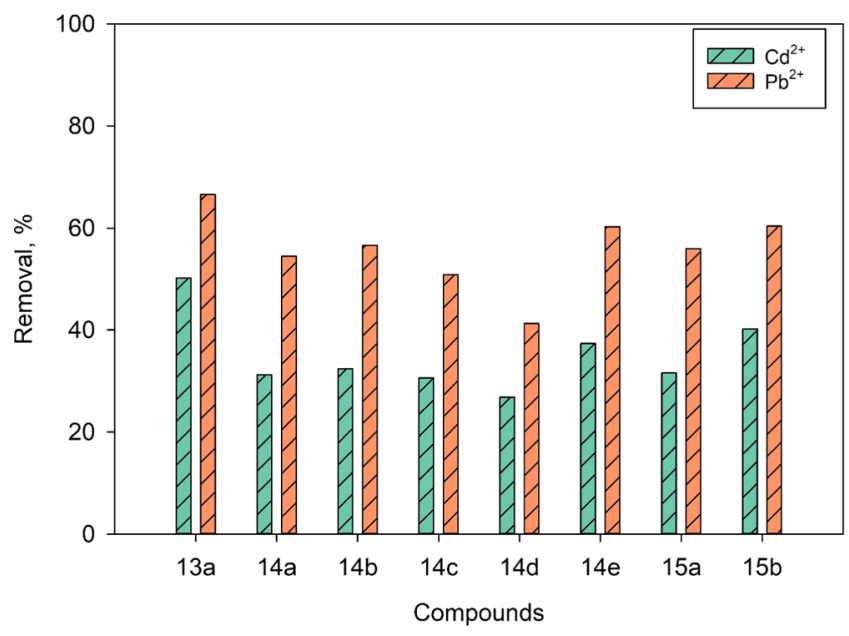

Figure 3. Lead and cadmium ion removal using s-triazolo[3,4b] $[1,3,4]$ thiadiazine derivatives.

14d, respectively. $15 a$ and $\mathbf{1 5 b}$ show 55.93 and $60.40 \%$ for $\mathrm{Pb}^{2+}$ and 31.56 and $40.19 \%$ for $\mathrm{Cd}^{2+}$, respectively.

It is worthy to note that the removal efficiencies of lead are higher than those of cadmium ions. This could be explained in terms of the adsorption capacity being related to the ionic radius, the outer electron configurations, and ionic charges of the metal ions. ${ }^{52}$ Although lead and cadmium have the same ionic charge, the outer electron configuration of cadmium is $3 \mathrm{~d}^{9}$, while for lead it is $6 \mathrm{~s}^{2}$. Moreover, the ionic radius of cadmium was smaller than that of lead. Thus, lead ion easily forms a stable electron configuration of $6 \mathrm{~s}^{2}$ when reacted with the compounds under study.

Inorganic Anion Removal. It is shown that the thiazolo-striazole, $3 \mathbf{a}-\mathbf{c}$, and $7 \mathbf{a}-\mathbf{d}, s$-triazolylthioacetophenone, $\mathbf{6 a}-\mathbf{d}$, 6-amino-thiazolo-s-triazole, $10 \mathrm{a}$ and $10 \mathrm{~b}, s$-triazolo[3,4-b]1,3,4-thiadiazine, 13a, 14a-e, and $s$-triazolo[3,4-b]-1,3,4thiadiazole, $\mathbf{1 5 a}$ and $\mathbf{1 5 b}$ derivatives have a potency for anionic contaminants from 1 to $94 \%$ removal for chloride, 6 to $100 \%$ removal for sulfate, and 9 to $100 \%$ for fluoride. Figure 4 demonstrates that the 1,3-thiazolo-s-triazoles produced by the reaction of $s$-triazole with aliphatic ketones $(3 \mathbf{a}-\mathbf{c})$ have higher efficiencies than those with aromatic ketones $(7 \mathbf{a}-\mathbf{d})$. For instance, 56.34, 92.62, and $79.67 \%$ removal of chloride; 10.65 ,

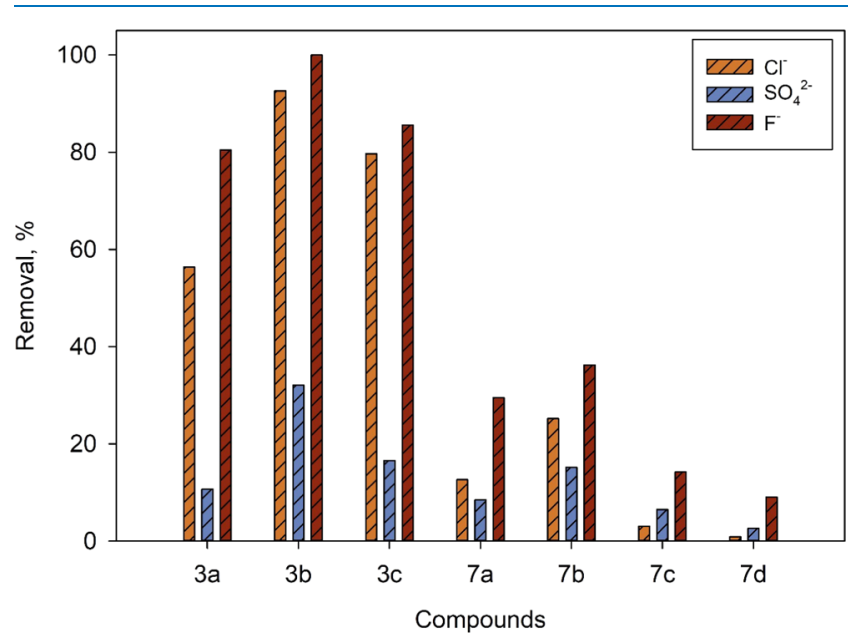

Figure 4. Chloride, fluoride, and sulfate removal using 1,3-thiazolo-striazole derivatives.
32.04 , and $16.54 \%$ removal of sulfate; and $80.47,100.00$, and $85.64 \%$ removal of fluoride were obtained using $3 a, 3 b$, and $3 c$, respectively. However, $7 \mathrm{a}, 7 \mathbf{b}, 7 \mathrm{c}$, and $7 \mathrm{~d}$ offered $12.61,25.17$, 3.02 , and $0.86 \%$ removal of chloride; $8.46,15.14,6.51$, and $2.56 \%$ removal of sulfate; and $29.46,36.15,14.20$, and $9.02 \%$ removal of fluoride, respectively.

Moreover, a range of chloride, sulfate, and fluoride removal from 19.29 to $33.74 \%, 94.09$ to $100.00 \%$, and 61.13 to $100.00 \%$, respectively, was found using $\mathbf{6 a}, \mathbf{6 b}, \mathbf{6 c}$, and $\mathbf{6 d}$ as illustrated in Figure 5. Regardless of the formation of the fused

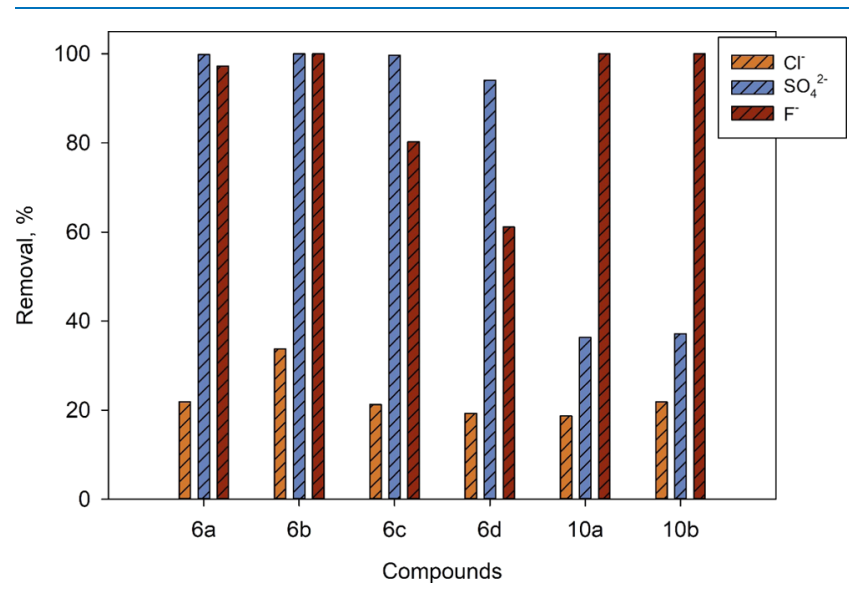

Figure 5. Chloride, fluoride, and sulfate removal using $s$ triazolylthioacetophenone derivatives.

ring, as indicated in $\mathbf{6 a - d}$ and $7 \mathbf{a}-\mathbf{d}$, it is clear that the donating group in the para position has higher efficiency for inorganic anions and in heavy metal ions than the withdrawing group in the para position. Also, the bromo group in the para position decreases the capacity of anion removal compared to the chloro group. This could be attributed to the larger size of bromine than chlorine. For example, 21.25 and $19.29 \%$ using $\mathbf{6 c}$ and $\mathbf{6 d}$ and 3.02 and $0.86 \%$ using $7 \mathrm{c}$ and $7 \mathbf{d}$ for chloride were obtained. Likewise, $6 \mathrm{c}$ and $6 \mathrm{~d}$ show 80.26 and $61.13 \%$ removal of fluoride, and 14.20 and $9.02 \%$ using $7 \mathrm{c}$ and $7 \mathrm{~d}$.

The reason for the high removal efficiency of fluoride compared to chloride could be attributed to the small size of fluorine in comparison to chlorine. The presence of two $-\mathrm{NH}_{2}$ groups enhances anion removal from aqueous solution compared to one $-\mathrm{NH}_{2}$ group as presented in $10 \mathbf{b}$ and 10a. For example, 18.70, 36.28, and $100 \%$ removal of chloride, sulfate, and fluoride were obtained using $10 \mathrm{a}$, while $10 \mathrm{~b}$ shows $21.84,37.14$, and $100 \%$ removal for chloride, sulfate, and fluoride, respectively.

Even though 14a-d compounds have the same donating and withdrawing functional groups as $7 \mathbf{a}-\mathbf{d}$, their removal capacities were found to be higher. This could be attributed to the fused ring of the six-membered ring having higher efficiency than five-membered rings. Thus, 88.27, 90.34, 68.12 , and $5.45 \%$ removal of chloride; $88.27,90.34,68.12$, and $5.45 \%$ removal of sulfate; and $88.27,90.34,68.12$, and $5.45 \%$ removal of fluoride were obtained using 14a, 14b, 14c, and $\mathbf{1 4 d}$, respectively, as shown in Figure 6. In addition, high capacities using 13a and 14e were acquired with 75.84 and $63.31 \%$ removal of fluoride, 94.14 and $93.69 \%$ removal of chloride, and 91.46 and $90.77 \%$ removal of sulfate. Furthermore, the acetamide group increases the removal percentage of inorganic anion contaminants. Therefore, the removal of fluoride, chloride, and sulfate with 100.00, 94.35, 


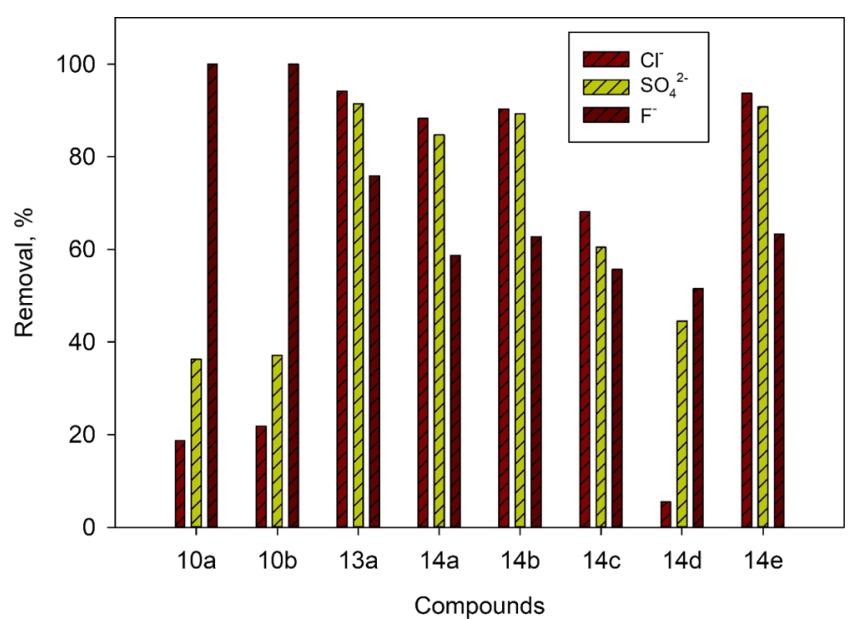

Figure 6. Chloride, fluoride, and sulfate removal using s-triazolo[3,4b] $[1,3,4]$ thiadiazines derivatives.

and $81.34 \%$, respectively, was obtained using $\mathbf{1 5 b}$. However, 15a demonstrates $96.48,20.90$, and $29.09 \%$ removal of fluoride, chloride, and sulfate, respectively.

Contaminant Removal Mechanism. The synthesized compounds based on the $s$-triazole derivatives' moieties have a powerful effect for anionic contaminant (i.e., chloride, sulfate, and fluoride) removal up to $100 \%$ but up to $76 \%$ for cationic contaminants' removal such as cadmium and lead. Thus, different adsorption processes may be discussed in terms of the physicochemical properties of the s-triazole derivatives, and thus the adsorption mechanism could be hypothesized. To explain this property, two aspects should be considered. First, the contaminant species at the studied $\mathrm{pH}$ and second the surface composition of the synthesized compounds may undergo a protonation reaction at the studied $\mathrm{pH}$ value. Therefore, high anion removal and low-to-moderate efficiencies for heavy metal ion removal were observed due to the presence of protons that induce the competitive adsorption reaction of proton ions for the existing adsorption sites. Another possibility is the production of protonated triazolium salts when the $s$-triazole heterocycle derivatives exist in an acidic medium. ${ }^{53}$ In this case, electrostatic attraction interactions led to the high affinity between inorganic anions and the synthesized triazole derivative compounds. But there is low attraction toward metal ions and the compounds under investigation. Consequently, elucidation of the removal mechanism of lead ions and fluoride using representative compounds under investigation $(\mathbf{6 b}$ and $\mathbf{1 0 b})$ is demonstrated in Figures S52 and S53. Figure S52 shows that the intensity of $-\mathrm{NH}$ and $-\mathrm{C}=\mathrm{O}$ functional groups of $\mathbf{6 b}$ decreased in the case of interaction either with lead or fluoride ions. Also, when $10 \mathrm{~b}$ reacted with fluoride or lead ions, it led to a decrease in the bands of $-\mathrm{NH}_{2}$ and $-\mathrm{C}=\mathrm{O}$ functional groups, as shown in Figure S53. Therefore, it is worth mentioning that the nitrogen and/or oxygen atoms of the s-triazole moiety act as donor ligands, and the unpaired electrons of oxygen and/or nitrogen atoms could create coordination bonds with $\mathrm{M}^{2+}$ ions leading to mono- or multinucleating ligand structures, as shown in Figure 7. The results are in agreement with those reported in the literature. ${ }^{54}$

\section{CONCLUSIONS}

In summary, we have developed an efficient and a one-pot protocol for the synthesis of 2,6-dimethyl-5-substitutedthiazolo[3,2-b]-s-triazoles $(\mathbf{3 a}-\mathbf{c}), 3$-methyl-s-triazolylthioacetophenone derivatives $(6 a-d)$, cyclized 6-aryl-2-methylthiazolo[3,2-b]-s-triazoles $(7 \mathbf{a}-\mathbf{d})$, and 6-amino-2-methyl-5substituted-thiazolo[3,2-b]-s-triazoles $(\mathbf{1 0 a}, \mathbf{b})$ through the interaction of 5-methyl-1H-s-triazole-3-thiol (1) with aliphatic and aromatic ketones and cyano compounds in refluxing acetic acid in the presence of a catalytic amount of sulfuric acid $\left(\mathrm{AcOH} / \mathrm{H}^{+}\right)$. Similarly, we studied the behavior of 4-amino-3methyl-s-triazole-5-thiol (12) with aliphatic and aromatic ketones and cyano compounds to produce 3-methyl-7H-striazolo[3,4-b]-1,3,4-thiadiazines (13a and 14a-e) and 3methyl-s-triazolo[3,4-b]-1,3,4-thiadiazole derivatives (15a,b). The present work shows the highest removal of lead with $45.59,76.29,63.53,64.77,66.55$, and $60.40 \%$ and cadmium with $29.75,52.39,47.26,48.26,50.24$, and $40.19 \%$ using $3 b$, $5 b, 6 b, 10 b, 13 a$, and 14b, respectively. Also, the thiazolo-striazole derivatives produced using aromatic ketones exhibited higher efficiencies for heavy metal ion removal compared to those produced using aliphatic amines. In addition, the isolated intermediate compounds of $s$-triazolylthioacetophenone present high removal of lead and cadmium ions in comparison to thiazolo-s-triazole derivatives. For example, $76.29 \%$ removal of lead was found using $\mathbf{5 b}$, while $\mathbf{6 b}$ shows $63.53 \%$ removal of lead ions. Furthermore, the methoxy group in the para position as the donating group shows a higher value of removal than<smiles>COC(CSC1NC(C)=NN1C1OCCO1)c1ccc(C)cc1</smiles><smiles>Cc1nc2sc(C)c(OCNc3c(C(N)=O)sc4nc(C)c5nc(C)nn5c34)n2n1</smiles>

6b

10b

$$
\mathbf{M}=\mathbf{P b}^{+2}, \mathbf{C d}^{+2}
$$

Figure 7. Possible mechanism for heavy metal ion removal using $6 \mathbf{b}$ and $10 \mathbf{b}$ compounds. 
chloro or bromo groups in the para position. For instance, $\mathbf{6 b}$ and $6 \mathrm{c}$ demonstrate 47.26 and $21.03 \%$ removal of lead, respectively. Hence, the adsorption capacity of lead was higher than that of cadmium due to its larger ionic radius. Moreover, $3 b, 5 b, 10 a, 10 b$, and $\mathbf{1 4 b}$ offer $100 \%$ removal of fluoride. Also, $92.62,33.74,25.17,21.84,94.14$, and $94.35 \%$ removal of chloride and 32.04, 100, 15.14, 37.14, 91.46, and $81.34 \%$ removal of sulfate were obtained using $3 b, 5 b, 6 b, 10 b, 13 a$, and $\mathbf{1 4 b}$. As indicated, the synthesized compounds based on $s$ triazole moieties show high efficiency for anions as well as cations. The possible mechanism of heavy metal ion removal could be attributed to coordination bond formation between the nitrogen or the oxygen atom with the metal ion to form a stable complex. Also, electrostatic interaction between inorganic anions and the compounds under investigation is the predominant explanation for anion removal from aqueous solution. Thus, further studies on the chemical formula of the formed complex should be performed using elemental analysis, and the optimum conditions of removal of both anionic and cationic contaminants simultaneously must be identified.

\section{EXPERIMENTAL SECTION}

Materials. Thiosemicarbazide, ethyl cyanoacetate, and malononitrile were purchased from Merck, Germany, and acetophenone from Prolabo, Paris. $p$-Chloroacetophenone and $p$-bromoacetophenone were purchased from Fluka, and $p$ methylacetophenone from Riedel-de Haen ag. Ethyl acetoacetate was purchased from Aldrich and benzoylacetone from Sigma. Acetylacetone and glacial acetic acid were purchased from El-Goumahouria. Sodium chloride $(\mathrm{NaCl})$, sodium sulfate $\left(\mathrm{Na}_{2} \mathrm{SO}_{4}\right)$, sodium fluoride $(\mathrm{NaCl})$, lead chloride $\left(\mathrm{PbCl}_{2}\right)$, cadmium chloride $\left(\mathrm{CdCl}_{2}\right)$, dithizone, chloroform $\left(\mathrm{CHCl}_{3}\right)$, potassium cyanide $(\mathrm{KCN})$, and hydroxylamine hydrochloride $\left(\mathrm{NH}_{2} \mathrm{Cl} \cdot \mathrm{H}_{2} \mathrm{O}\right)$ were purchased from SigmaAldrich, Germany. All solutions were prepared with Milli-Q water and filtered using a $0.22 \mu \mathrm{m}$ Nylon membrane filter.

Synthetic Procedures. The general procedure for the synthesis of 2,6-dimethyl-5-substituted-1,3-thiazolo[3,2-b]-striazole $(3 \mathbf{a}-\mathbf{c}), 3$-methyl-s-triazolylthioacetophenone derivatives $(\mathbf{6 a}-\mathbf{d}), 2$-methyl-6-aryl-1,3-thiazolo[3,2-b]-s-triazole $(7 \mathbf{a}-\mathbf{d})$, and 6-amino-2-methyl $[1,3]$ thiazolo[3,2-b]-s-triazole5-carboxylate $(\mathbf{1 0 a}, \mathbf{b})$ is as follows. Briefly, 5-methyl-1H-striazole-3-thiol $(1,0.008 \mathrm{~mol})$ was added to a solution of aliphatic ketones $(\mathbf{2 a}-\mathbf{c}, 0.008 \mathrm{~mol})$, aromatic ketones $\mathbf{5 a}-\mathbf{d}$ $(0.008 \mathrm{~mol})$, or cyano compounds $(9 \mathrm{a}, \mathrm{b}, 0.008 \mathrm{~mol})$ in glacial acetic acid $(20 \mathrm{~mL})$ with a catalytic amount of conc. $\mathrm{H}_{2} \mathrm{SO}_{4}$. Then, the mixture was refluxed for $5 \mathrm{~h}$. After cooling to room temperature, the reaction mixture was diluted with $\mathrm{H}_{2} \mathrm{O}(10$ $\mathrm{mL}$ ) and neutralized with $\mathrm{NH}_{3}$ solution. The obtained crude product was collected by filtration, washed with $\mathrm{H}_{2} \mathrm{O}$, and crystallized from the appropriate solvent to give the desired products $3 a-c, 6 a-d, 7 a-d$, or $10 a, b$ in good yield.

The general procedure for the synthesis of 3-methyl-6,7disubstituted-7H-s-triazolo[3,4- $b]$-1,3,4-thiadiazines (13a and $14 \mathbf{a}-\mathbf{d})$ and 3-methyl-6-substituted-s-triazolo[3,4-b][1,3,4]thiadiazoles $(\mathbf{1 5 a}, \mathbf{b})$ is as follows. Briefly, 4-amino-5-methyl$4 \mathrm{H}$-s-triazole-3-thiol $(\mathbf{1 2}, 0.008 \mathrm{~mol})$ was added to a solution of ketones $(\mathbf{2 c}, \mathbf{5 a}-\mathbf{e}, 0.008 \mathrm{~mol})$ or cyano compounds $(\mathbf{9 a}, \mathbf{b}$, $0.008 \mathrm{~mol})$ in glacial acetic acid $(20 \mathrm{~mL})$ with a catalytic amount of conc. $\mathrm{H}_{2} \mathrm{SO}_{4}$. Then, the mixture was refluxed for 3 h. After cooling to room temperature, the reaction mixture was diluted with $\mathrm{H}_{2} \mathrm{O}(10 \mathrm{~mL})$ and neutralized with $\mathrm{NH}_{3}$ solution. The obtained crude product was collected by filtration, washed with $\mathrm{H}_{2} \mathrm{O}$, and crystallized from the appropriate solvent to give the desired products $13 \mathbf{a}, \mathbf{1 4} \mathbf{a}-\mathbf{d}$, or $15 \mathbf{a}, \mathbf{b}$ in excellent yield.

\section{ASSOCIATED CONTENT}

\section{Supporting Information}

The Supporting Information is available free of charge at https://pubs.acs.org/doi/10.1021/acsomega.1c03675.

Reaction mechanisms, synthetic procedures, electronic energy calculations, and spectral data of the synthetic compounds and adsorption experiments and mechanisms of the synthetic compounds (PDF)

\section{AUTHOR INFORMATION}

\section{Corresponding Authors}

Ahmed F. M. EL-Mahdy - Chemistry Department, Faculty of Science, Assiut University, Assiut 71516, Egypt; Department of Materials and Optoelectronic Science, National Sun YatSen University, Kaohsiung 80424, Taiwan; (1) orcid.org/ 0000-0002-5237-750X; Email: ahmedelmahdy@ mail.nsysu.edu.tw, ahmed.ahmed20@science.au.edu.eg

Hassan A. H. El-Sherief - Chemistry Department, Faculty of Science, Assiut University, Assiut 71516, Egypt;

Email: helsherief@aun.edu.eg

\section{Authors}

Zeinab A. Hozien - Chemistry Department, Faculty of Science, Assiut University, Assiut 71516, Egypt

Laila S. A. Ali - Chemistry Department, Faculty of Science, Assiut University, Assiut 71516, Egypt

Ahmad Abo Markeb - Chemistry Department, Faculty of Science, Assiut University, Assiut 71516, Egypt

Complete contact information is available at: https://pubs.acs.org/10.1021/acsomega.1c03675

\section{Notes}

The authors declare no competing financial interest.

\section{ACKNOWLEDGMENTS}

The authors thank the Assiut University (Egypt) for financial support and the Department of Materials and Optoelectronic Science, National Sun Yat-Sen University (Taiwan), for enabling them to utilize the NMR apparatus.

\section{REFERENCES}

(1) Karegoudar, P.; Prasad, D. J.; Ashok, M.; Mahalinga, M.; Poojary, B.; Holla, B. S. Synthesis, antimicrobial and antiinflammatory activities of some 1,2,4-triazolo[3,4-b][1,3,4]thiadiazoles and 1,2,4-triazolo[3,4-b][1,3,4] thiadiazines bearing trichlorophenyl moiety. Eur. J. Med. Chem. 2008, 43, 808-815.

(2) Isloor, A. M.; Kalluraya, B.; Shetty, P. Synthesis, characterization and pharmacological studies of some new Mannich bases derived from 1,2,4-triazoles. Eur. J. Med. Chem. 2009, 44, 3784-3787.

(3) Padmavathi, V.; Thriveni, P.; Reddy, G. S.; Deepti, D. Synthesis and antimicrobial activity of novel sulfone-linked bis heterocycles. Eur. J. Med. Chem. 2008, 43, 917-924.

(4) Amir, M.; Kumar, H.; Javed, S. A. Condensed bridgehead nitrogen heterocyclic system: Synthesis and pharmacological activities of 1,2,4-triazolo-[3,4-b]-1,3,4-thiadiazole derivatives of ibuprofen and biphenyl-4-yloxy acetic acid. Eur. J. Med. Chem. 2008, 43, 2056-2066.

(5) Sztanke, K.; Tuzimski, T.; Rzymowska, J.; Pasternak, K.; Szerszen, M. Synthesis, determination of the lipophilicity, anticancer and antimicrobial properties of some fused 1,2,4-triazole derivatives. Eur. J. Med. Chem. 2008, 43, 404-419. 
(6) Kuş, C.; Ayhan-Kılcıgil, G.; Zbey, S.; Kaynak, F. B.; Kaya, M.; Coban, T.; Can-Eke, B. Synthesis and antioxidant properties of novel $\mathrm{N}$-methyl-1,3,4-thiadiazol-2-amine and 4-methyl-2H-1,2,4-triazole$3(4 \mathrm{H})$-thione derivatives of benzimidazole class. Bioorg. Med. Chem. 2008, 16, 4294-4303.

(7) Mohamed, M. G.; Ahmed, M. M.; Du, W. T.; Kuo, S. W. 2021. Meso/microporous carbons from conjugated hyper-crosslinked polymers based on tetraphenylethene for high-performance $\mathrm{CO} 2$ capture and supercapacitor. Molecules 2021, 26, No. 738.

(8) Danko, M.; Mosnáček, J.; Kuo, S. W.; Lukáč, I. Crosslinking of polystyrene film by di (4-dibenzoyl peroxide) ether synthesized or formed in situ using visible light-induced photo-peroxidation of 4,4'oxydibenzil. J. Photochem. Photobiol., A 2020, 403, No. 112849.

(9) Mohamed, M. G.; Atayde, E. C., Jr.; Matsagar, B. M.; Na, J.; Yamauchi, Y.; Wu, K. C. W.; Kuo, S. W. Construction hierarchically mesoporous/microporous materials based on block copolymer and covalent organic framework. J. Taiwan Inst. Chem. Eng. 2020, 112, 180-192.

(10) Mohamed, M. G.; Meng, T. S.; Kuo, S. W. Intrinsic watersoluble benzoxazine-functionalized cyclodextrin and its formation of inclusion complex with polymer. Polymer 2021, 226, No. 123827.

(11) Holla, B. S.; Akberali, P. M.; Shivananda, M. K. Studies on nitrophenylfuran derivatives: Part XII. Synthesis, characterization, antibacterial and antiviral activities of some nitrophenylfurfurylidene1,2,4-triazolo[3,4-b]-1,3,4-thiadiazines. Il Farmaco 2001, 56, 919927.

(12) Holla, B. S.; Poojary, K. N.; Rao, B. S.; Shivananda, M. K. New bis-aminomercaptotriazoles and bis-triazolothiadiazoles as possible anticancer agents. Eur. J. Med. Chem. 2002, 37, 511-517.

(13) Khattab, T. A.; Rehan, M. Synthesis and characterization of bisazo 1, 2, 4, 5-tetrazine dyestuff. J. Text. Color. Polym. Sci. 2018, 15, $33-36$.

(14) Sayeed, A.; Akram, M. W.; et al. Studies on the Synthesis of some new 1, 2, 4-Triazoles Derivatives and Evaluation for their AntiTubercular activity profiles. Res. J. Pharm. Technol. 2018, 11, 153164.

(15) Olesiejuk, M.; Kudelko, A.; Swiatkowski, M.; Kruszynski, R. Synthesis of 4-alkyl-4H-1, 2, 4-triazole derivatives by Suzuki crosscoupling reactions and their luminescence properties. Molecules 2019, 24, No. 652.

(16) El-Sebaey, S. A. Recent Advances in 1,2,4-Triazole Scaffolds as Antiviral Agents. ChemistrySelect 2020, 5, 11654-11680.

(17) Peyton, L. R.; Gallagher, S.; Hashemzadeh, M. Triazole antifungals. a review. Drugs Today 2015, 51, 705-718.

(18) El-Sherief, H. A. H.; Hozien, Z. A.; El-Mahdy, A. F. M.; Sarhan, A. A. O. Intramolecular Cyclization of Mannich Reaction for Synthesis of Pyrimido [2, 1-b]-1, 3, 5-Tiadiazines. J. Heterocycl. Chem. 2010, 47, 1294-1302.

(19) Gupta, J. K.; Mishra, P. Antimicrobial and anthelmintic activities of some newly synthesized triazoles. Asian J. Pharm. Clin. Res. 2017, 10, 139.

(20) Hu, G. Q.; Hou, L. L.; Xie, S. Q.; Hunag, W. L. Synthesis and antitumor activity of asymmetric bis(s-triazole Schiff-base)s. Chin. J. Org. Chem. 2008, 28, 700-704.

(21) Abdelrehim, E. M. Synthesis and Screening of New $[1,3,4]$ Oxadiazole, $[1,2,4]$ Triazole, and $[1,2,4]$ Triazolo $[4,3-b][1,2,4]$ triazole Derivatives as Potential Antitumor Agents on the Colon Carcinoma Cell Line (HCT-116). ACS Omega 2021, 6, 1687-1696.

(22) Santhanalakshmi, K.; Margandan, K.; Manivannan, P. A. N. Overview of Triazole Scaffold: Synthesis and Pharmacological Significance (2010-2020). Eur. J. Mol. Clin. Med. 2020, 7, 5580-5590.

(23) Gupta, D.; Jain, D. K. Synthesis, antifungal and antibacterial activity of novel 1,2,4-triazole derivatives. J. Adv. Pharm. Technol. Res. 2015, 6, 141-146.

(24) Assis, S. P. D. O.; Silva, M. T. D.; Oliveira, R. N. D.; Lima, V. L. D. M. Synthesis and Anti-Inflammatory Activity of New AlkylSubstituted Phthalimide 1H-1,2,3-Triazole Derivatives. Sci. World J. 2012, 2012, No. 925925.
(25) Dixit, D.; Verma, P. K.; Marwaha, R. K. A review on 'triazoles': their chemistry, synthesis and pharmacological potentials. J. Iran. Chem. Soc. 2021, 2535-2565.

(26) Dharavath, R.; Boda, S. A synthesis and biological screening of newly substituted 9-methyl-6-aryl-[1, 2, 4] triazolo $[4,3-\mathrm{a}][1,8]$ naphthyridines using chloranil. Synth. Commun. 2019, 49, 17411749.

(27) Shaikh, M. H.; Subhedar, D. D.; Nawale, L.; Sarkar, D.; Khan, F. A. K.; Sangshett, J. N.; Shingate, B. B. 1,2,3-Triazole derivatives as antitubercular agents: synthesis, biological evaluation and molecular docking study. Med. Chem. Commun. 2015, 6, 1104-1116.

(28) Ahmadi, F.; Ghayahbashi, M. R.; Sharifzadeh, M.; Alipoiur, E.; Ostad, S. N.; Vosooghi, M.; Amini, M.; et al. Synthesis and evaluation of anti-inflammatory and analgesic activities of new 1,2,4-triazole derivatives. Med. Chem. 2014, 11, 69-76.

(29) Radwan, A. A.; Alanazi, F. K.; Al-Agamy, M. H. 1, 3, 4Thiadiazole and 1, 2, 4-triazole-3 (4H)-thione bearing salicylate moiety: synthesis and evaluation as anti-Candida albicans. Braz. J. Pharm. Sci. 2017, 53, 1-12.

(30) Siddiqui, A. A.; Mishra, R.; Kumar, R.; Rashid, M.; Khaidem, S. Synthesis, spectral characterization, and pharmacological screening of some 4-[\{1-(aryl)methylidene $\}$-amino]-3-(4-pyridyl)-5-mercapto-4H1,2,4-triazole derivatives. J. Pharm. BioAllied Sci. 2010, 2, 109-112.

(31) Saremi, K.; Rad, S. K.; Tayeby, F.; Abdulla, M. A.; Karimian, H.; Majid, N. A. Gastroprotective activity of a novel Schiff base derived dibromo substituted compound against ethanol-induced acute gastric lesions in rats. BMC Pharmacol. Toxicol. 2019, 20, No. 13.

(32) Kaur, R.; Dwivedi, A. R.; Kumar, B.; Kumar, V. Recent Developments on 1,2,4-Triazole Nucleus in Anticancer Compounds: A Review. Anticancer Agents Med. Chem. 2016, 16, 465-489.

(33) Kharb, R.; Sharma, P. C.; Yar, M. S. Pharmacological significance of triazole scaffold. J. Enzyme Inhib. Med. Chem. 2011, 26, $1-21$.

(34) El-Mahdy, A. F. M.; El-Sherief, H. A. H.; Hozien, Z. A.; Kuo, Sh-W. AConvenient One-Pot and RapidMicrowave-Assisted Synthesis of Biologically Active s-Triazolo [3, 4-b] $[1,3,4]$ Thiadiazine and sTriazolo [3, 4-b][1, 3, 4] Thiadiazole Nanoarchitectonics. J. Nanosci. Nanotechnol. 2020, 20, 2917-2929.

(35) Shawali, A. S.; Zeid, I. F.; Abdelkader, M. H.; El-Sherbini, A. M.; et al. Synthesis, Acidity Constants and Tautomeric Structure of 7Arylhydrazono[ $1,2,4]$ Triazolo[3,4-b] $[1,3,4]$ thiadiazines in Ground and Excited States. J. Chin. Chem. Soc. 2001, 48, 65-72.

(36) El-Dawy, M. A.; Omar, A. M. M. E.; Ismail, A. M.; Hazzaa, A. A. B. Potential Broad Spectrum Anthelmintics IV: Design, Synthesis, and Antiparasitic Screening of Certain 3,6-Disubstituted- (7H) striazolo- $[3,4-\mathrm{b}][1,3,4]$ thiadiazine Derivatives. J. Pharm. Sci. A 1983, $72,45-50$.

(37) Heravi, M. M.; Rahimizadeh, M.; Seyf, M.; Davoodnia, A.; Ghassemzadeh, M. Bicyclic compounds derived from 4-amino-3mercapto-1,2,4-triazoles: Facile routes to 1,2,4-triazolo[3,4-b][1,3,4]thiadiazoles and 1,2,4-triazolo[3,4-b] [1,3,4]thiadiazines. Phosphorus Sulfur Relat. Elem. 2000, 167, 211-217.

(38) Eweiss, N.; Bahajaj, A. Synthesis of heterocycles. Part VII Synthesis and antimicrobial activity of some $7 \mathrm{H}$-s-triazolo $[3,4-\mathrm{b}][1$, $3,4]$ thiadiazine and s-triazolo $[3,4-b][1,3,4]$ thiadiazole derivatives. $J$. Heterocycl. Chem. 1987, 24, 1173-1182.

(39) Farghalya, A.-R.; Clercq, E. D.; El-Kashefa, H. Synthesis and antiviral activity of novel $[1,2,4]$ triazolo $[3,4-\mathrm{b}][1,3,4]$ thiadiazoles, $[1,2,4]$ triazolo[3,4-b][1,3,4] thiadiazines and $[1,2,4]$ triazolo[3,4-b][1,3,4] thiadiazepines. ARKIVOC 2006, 2006, 137-151.

(40) Abdel-Wahab, B. F.; Mohamed, H. A. Direct Routes to Thiazolotriazoles by Cyclization. Phosphorus Sulfur Relat. Elem. 2014, $189,157-179$

(41) Hozien, Z. A.; El-Mahdy, A. F. M.; Abo Markeb, A.; Ali, L. S. A.; H E-Sherief, A. H. Synthesis of Schiff and Mannich bases of new striazole derivatives and their potential applications for removal of heavy metals from aqueous solution and as antimicrobial agents. RSC Adv. 2020, 10, 20184-20194. 
(42) El-Mahdy, A. F. M.; E-Sherief, H. A. H. An Efficient and Rapid Intramolecular Cyclization of a QuadrupleMannich Reaction for OnePot Synthesis of Pentaazaphenalenes and Their Antimicrobial Activities. RSC Adv. 2016, 6, 92134-92143.

(43) El-Mahdy, A. F. M.; Mohamed, O. S.; El-Sherief, H. A. H.; Hozien, Z. A. An Efficient One-Pot Synthesis ofBenzo[1,4]Thiazines, Benzo[1,3]Thiazoles and Benzo[1,5]Thiazepines. Curr. Org. Synth. 2017, 14, 604-611.

(44) El-Mahdy, A. F. M.; El-Sherief, H. A. H.; Hozien, Z. A. Convenient One-Pot Four-Component Synthesis of 6,8-Disubstituted-5,6,7,8-Tetrahydropyrimido[4,5-d]Pyrimidin-4(3H)-Ones via a Triple Mannich Reaction. Aust. J. Chem. 2019, 72, 542.

(45) El-Sherief, H. A. H.; Hozien, Z. A.; El-Mahdy, A. F. M.; Sarhan, A. A. O. Novel Method for the Synthesis of s-Triazolo[3,4b] $[1,3,4]$ thiadiazines. Synthesis 2010, 2636-2642.

(46) Hozien, Z. A.; El-Mahdy, A. F. M.; El-Sherief, H. A. H.; Sarhan, A. A. O. One pot synthesis and reactions of novel 5 -amino[1,3]thiazolo[3,2- b][1,2,4] triazoles. ARKIVOC 2011, 2011, 71-84.

(47) Markeb, A. A.; Alonso, A.; Sánchez, A.; Font, X. Adsorption process of fluoride from drinking water with magnetic core-shell CeTi@Fe3O4 and Ce-Ti oxide nanoparticles. Sci. Total Environ. 2017, 598, 949-958.

(48) Markeb, A. A.; Ordosgoitia, L. A.; Alonso, A.; Sanchez, A.; Font, X. Novel magnetic core-shell Ce-Ti@Fe3O4 nanoparticles as an adsorbent for water contaminants removal. RSC Adv. 2016, 6, 56913-56917.

(49) Ali, H.; Khan, E.; Sajad, M. A. Phytoremediation of heavy metals concepts and applications. Chemosphere 2013, 91, 869-881.

(50) Dotto, G. L.; McKay, G. Current scenario and challenges in adsorption for water treatment. J. Environ. Chem. Eng. 2020, 8, No. 103988.

(51) Mokadem, Z.; Mekki, S.; Saidi-Besbes, S.; Agusti, G.; Elaissari, A.; Derdour, A. Triazole containing magnetic core-silica shell nanoparticles for $\mathrm{Pb} 2+, \mathrm{Cu} 2+$ and $\mathrm{Zn} 2+$ removal. Arab. J. Chem. 2017, 10, 1039-1051.

(52) Zhu, L.; Zhang, L.; Tang, Y. Synthesis of Montmorillonite/ Poly(acrylic acid-co-2-acrylamido-2-methyl-1-propane sulfonic acid) Superabsorbent Composite and the Study of its Adsorption. Bull. Korean Chem. Soc. 2012, 33, 1669-1674.

(53) Dehaen, W.; Bakulev, V. A. Chemistry of 1,2,3-Triazoles; Topics in Heterocyclic Chemistry; Springer, 2015; Vol. 40, p 384.

(54) Badruddoza, A. Z. M.; Tay, A. S. H.; Tan, P. Y.; Hidajat, K.; Uddin, M. S. Carboxymethyl- $\beta$-cyclodextrin conjugated magnetic nanoparticles as nano-adsorbents for removal of copper ions: Synthesis and adsorption studies. J. Hazard. Mater. 2011, 185, $1177-1186$. 